\title{
Tenofovir Renal Toxicity: Evaluation of Cohorts and Clinical Studies_-Part 2
}

\author{
Adikwu Elias $^{*}$, Ogbuehi Ijeoma ${ }^{1}$, Nkereuwen Jonathan Edikpo ${ }^{1}$, Deo Oputiri ${ }^{2}$ \\ Oru-Bo Precious Geoffrey² \\ ${ }^{1}$ Department of Pharmacology, Faculty of Basic Medical Sciences, University of Port Harcourt, Choba, Rivers State, Nigeria; ${ }^{2}$ De-
partment of Pharm Tech, College of Health Sciences, Otuogidi, Bayelsa State, Nigeria. \\ Email: ${ }^{*}$ adikwuelias@gmail.com
}

Received December $2^{\text {nd }}, 2013$; revised December 29 $9^{\text {th }}$, 2013; accepted January $12^{\text {th }}, 2014$

Copyright (C) 2014 Adikwu Elias et al. This is an open access article distributed under the Creative Commons Attribution License, which permits unrestricted use, distribution, and reproduction in any medium, provided the original work is properly cited. In accordance of the Creative Commons Attribution License all Copyrights @ 2014 are reserved for SCIRP and the owner of the intellectual property Adikwu Elias et al. All Copyright (C) 2014 are guarded by law and by SCIRP as a guardian.

\section{ABSTRACT}

Tenofovir is a nucleotide reverse transcriptase inhibitor used as part of antiretroviral regimens. It is well tolerated with relative toxicological effects but recent reports have linked it with renal toxicity which is of clinical concern. This study reviews literary work on tenofovir renal toxicity with more light on case reports. Tenofovir renal toxicity manifests as Fanconi's syndrome, nephrogenic diabetes insipidus and acute renal failure. Fanconi's syndrome is characterised by acidosis, protenuria, albuminuria, aminoaciduria, hyperchloremic, metabolic acidosis, hypouricemia, hypophosphatemia and glycosuria. The presence of urine osmolality, polydipsia and polyuria could give credence totenofovir induced nephrogenic diabetes insipidus. In some cases of tenofovir renal toxicity, renal biopsy revealed sclerosed glomeruli with ischemic injury including portal collapse of capillary loops. Histopathological changes in glumeruli include mild mesangial proliferation, increased mesangial matrix and thickened capillary loops. Moderate degenerative tubular changes, loss of tubular mass, interstitial scarring and scattered cellular infiltrates. Pharmacodynamic and pharmacokinetic interactions may occur with the co administration of tenofovir with non steroidal anti-inflammatory drugs, aminoglycosides and some protease inhibitors which may potentiate renal toxicity. Tenofovir renal toxicity is associated with some risk factors including genetic polymorphism as supported by dichotomy in renal toxicity among different race and the association between $A B C C 2$ gene and tenofovir kidney tubular dysfunction. The pharmacology of tenofovir renal toxicity is unclear but it is attributed to the interaction between tenofovir and theorganic anion transporters (hOAT1, and to a lesser extent, OAT3) favoring intracellular accumulation in renal proximal tubule cells. This may lead to ultrastructural mitochondrial abnormalities and decreased mtDNA levels which could stimulate reactive oxygen species production, depletion of antioxidants and antioxidant enzymes. These processes can stimulate the destruction of biomolecules such as DNA, proteins, and lipids, thus causing the deregulation of redox-sensitive metabolic pathways, signaling pathways, and cell death. Despite tenofovir renal toxicity it has achieved notable therapeutic success nevertheless patients on tenofovir containing regimens should be monitored for renal function parameters. Co administration with potential nephrotoxic drugs should be avoided except when benefit outweighs risk.

\section{KEYWORDS}

Tenofovir; Renal; Toxicity; Interactions; Polymorphism; Pharmacology

\section{Introduction}

The nephron is the functional unit of the kidney and consists of a continuous tube of highly specialized heteroge-

*Corresponding author. neous cells. It is the major organ of excretion and homeostasis for water-soluble molecules; it can concentrate certain substances actively. Its cells can bioconvert chemicals and metabolically activate a variety of chemical substances [1]. To limit both systemic exposure and 
the duration of the pharmacological or toxicological effects, of these substances they are rapidly and efficiently eliminated via the kidney as part of the fundamental defense system of our body. Some drug substances are actively transported across the renal proximal tubule by drug transporters followed by elimination via the urine which is a major pathway in the detoxification process [2]. Some of these eliminated drugs are toxic and their contact with drug transporters in tubular cells is the first fundamental stage in the development of their nephrotoxic process. Most drug substances become nephrotoxic only after transportation into the proximal tubular cells. Recent advances have identified families of drug transporters which are expressed in the proximal tubule [3]. Of the identified transporters, the organic anion transporters (hOAT1, and to a lesser extent, OAT3) in the basolateral membrane are responsible for the active transportation of tenofovir into renal proximal tubule cells $[4,5]$, subsequently the drug is secreted to the tubular lumen by the apical membrane transporters (multidrug resistance proteins, 4 and 2) [6]. Tenofovir may interact with these transporters leading to excessive entry or reduced outflow of tenovoir favoring intracellular accumulation and increasing renal toxicity. Proximal tubular cell secretion of tenofovir explains the accumulation of the drug in these mitochondria-rich cells leading to mitochondrial damage. Despite initial evaluations which gave credence to the renal safety of tenofovir, reports have associated tenofovir with significant risk of renal toxicity in human and animal studies. Tenofovir nephrotoxicity is characterized by proximal tubular cell dysfunction that may be associated with acute kidney injury or chronic kidney injury [7]. Several case reports describing renal toxicity attributable to tenofovir have been published, with manifestations of Fanconi syndrome, nephrogenic diabetes insipidus and acute renal failure being reported $[8,9]$. Fanconi's syndrome is characterised by acidosis, protenuria, aminoaciduria, hypophosphatamia and glycosuria [10]. In some cases histopathological changes in renal toxicity revealed proximal tubular injury and varying degrees of chronic tubulointerstitial scarring. Prominent eosinophilic inclusions within proximal tubular cell cytoplasm and alteration in mitochondria structure and function were also observed [11,12]. Due to tenofovir reported renal toxicity, in our initial study - Part one, we critically looked at cohorts and clinical studies. In this second part, we are evaluated case reports, genetic factors, pharmacology of tenofovir renal toxicity and the implications of drug-drug interactions on tenofovir renal toxicity.

\section{Types of Renal Toxicity in HIV}

In spite the fact that some antiretroviral drugs are associated with renal toxicity, HIV is also associated with some forms of renal damage (nephropathy). In the first part of this work we reviewed HIV associated renal nephropathy, HIVAN was observed to be prominent in HIV positive patients of African origin. This observation was reported to have genetic predisposition, and incidence is equally associated with higher viral load. Researchers were able to classify HIV associated renal nephropathy probably due to the evaluation of different and unique characteristic manifestations. Commonly known classifications include HIV associated nephropathy (HIVAN), immune complex-mediated glomerulonephritis, andthrombotic microangiopathies (TMA).

\subsection{HIV Associated Nephropathy}

It is a disease caused by focal glomerulosclerosis with severe proteinuria, renal failure, and rapid progression to ESRD. It has become the most common cause of end stage renal disease in HIV patients. Studies have shown that HIVAN is more prevalent in patients of African descent $[13,14]$. The estimated prevalence of HIVAN has ranged from $3.5 \%$ in clinical studies to $12 \%$ in autopsy studies [15]. Renal biopsy is one of the most fundamental means to establish the diagnosis of HIVAN. Characteristic histopathological findings include collapsing focal and segmental glomerulosclerosis, tubular epithelial atrophy with microcystic dilatation of the tubules and lymphocytic interstitial infiltration [16]. Viral infection of renal cells seems to play an important role in the pathogenesis of HIVAN. In 2002 Marras and others reported that renaltubular cells in patients with HIVN could serve as a reservoir which facilitates active replication of HIV-1 independent of various peripheral blood mononuclear cells [17].

\subsection{Immune Complex-Mediated Glomerulonephritis}

A multitude of immune complex-mediated glomerulonephritis have been reported as causes of chronic kidney disease in HIV infected patients. The prevalence of HIV associated, immune complex-mediated glomerulonephritis has been estimated to be $15 \%-80 \%$ in various autopsy and biopsy study in HIV infected patients. According to some authors Immune complex-mediated glomerulonephritis may present as postinfectious glomerulonephritis, membranous nephritis, IgA nephritis, fibrillary glomerulonephritis, immunotactoid glomerulopathy, and membranoproliferative glomerulonephritis [18]. In general, HIVAN is mainly limited to patients of African descent, whereas most cases of renal disease in the white population seem to be immune complex-mediated glomerulonephritis [19].

\subsection{Thrombotic Microangiopathies (TMA)}

Thrombotic microangiopathies involving kidney was first 
described in AIDS patient by Boccia et al. in 1984, but subsequently, several hundred cases have been reported worldwide [20]. TMA occurs with an annual incidence of 3.7 cases per 100000 persons in the general population and is lightly more common in females (female:male ratio 3:2) [21-23]. TMA is a heterogeneous group of disorders characterized by histopathological lesion of vessel wall thickening (mainly arterioles or capillaries), intraluminal platelet thrombosis and obstruction of the vessel lumina. Consumption of platelets and erythrocytes occurs in the microvasculature of kidney, brain and other organs, which causes laboratory features of thrombocytopenia and microangiopathic hemolytic anemia [24]. Haemolytic uraemic syndrome (HUS) and thrombotic thrombocytopenic purpura (TTP) are classical forms of thrombotic microangiopathy (TMA) which are characterize by microangiopathic haemolytic anaemia with renal insufficiency along with other features such as thrombocytopenia, fever, and neurological changes [25,26]. It can also be observed in association with pregnancy, cancer, chemotherapy, human immunodeficiency (HIV) infection and malignant hypertension [27].

\section{Role of Antiretroviral in HIV Associated Renal Disease}

Despite HIV associate renal disease the advent of highly active antiretroviral therapy in the management of HIV hasdecreases the incidence of HIV associated renal disease. One of the primary impacts that is vividly visible is the decrease in HIV associated mortality and morbidity rates. A clearer picture of conspicuous impact could be ascertained from the outstanding literary work of Wyatt and Klotman [28] who reported that the widespread introduction of HAART in 1996, led to a drastic decline in AIDS-related deaths in the United States. They further stated that the proportion of deaths that are attributable to AIDS-defining conditions has continued to decline, with chronic complications such as liver and kidney disease becoming increasingly important contributors to mortality in the HAART era. At the same time, there has been a more subtle decrease in the incidence of ESRD related to HIV, which reached a plateau at approximately 800 to 900 new cases per year in the United States.

Schwartz and colleagues also showed that the introduction of HAART has had a significant impact on the epidemiology of HIV-related kidney disease, the decline in the incidence of HIV-related ESRD after the introduction of HAART strongly suggested a role for antiretroviral therapy in the treatment of HIVAN [29]. This is further supported by reports of clinical and histological improvement in kidney function and architecture after the initiation of HAART [30,31] and by retrospective cohort studies [32]. A number of cohorts have shown tremendous improvement in renal function of HIV patients with renal impairment observed after initiation of HAART. In one of the cohorts HIV positive renal impaired patients improved with HAART treatment with respect to non HAART treated patients [33]. Also Preliminary data from 3313 patients who were enrolled in a randomized antiretroviral trial in Uganda and Zimbabwe demonstrated stabilization or slight improvement in kidney function after the initiation of HAART [34]. In a comparative cohort of patients with HIV biopsy proven HIVAN in the pre-HAART and in the HAART era reports revealed improvement in HIV associated renal function during the HAART era [35]. A cohort of 263 consecutive HIV-infected patients referred to the Johns Hopkins renal clinic from 1995 to 2004 was examined. Patients were included if they had biopsy-proven HIVAN and did not require dialysis within 1 month of their kidney biopsy. Fifty-three patients among 152 biopsied patients had HIVAN. Among 36 patients who met the inclusion criteria, 26 were treated with ART (group I) and 10 patients were not (group II). It was observed that Patients with biopsy-proven HIVAN treated with ART had better renal survival compared with patients who did not receive ART [36].

The beneficial effects of HAART on HIV associated renal disease have been shown in individual clinical observations. There are reports of resolution of renal disease with the administration of HAART, with a recurrence of renal disease after stopping treatment [37]. It is recognized that HAART prevents or reduces the risk of developing HIVAN and if this occurs, HAART treated patients may have a slower course and lower mortality than in untreated patients [38]. Successful transplantations in HIV-infected patients who have received highly active antiretroviral therapy and have undetectable viral loads have been reported. One of these reports can be seen from the work of Murphy and colleagues who transplanted kidneys in 23 patients who were receiving antiretroviral therapy and observed a graft survival rate of $87 \%$. Case reports have also shown the impact of antiretroviral drugs on HIV associated renal disease [39]. Also two African Americans with HIV associated renal impairment exhibited marked improvement after initiation of antiretroviral drugs [40]. Notwithstanding the impact of antiretroviral therapy on HIV associated renal disease is not without its problems. Reports have associated some antiretroviral drugs with renal toxicity which manifested as acute renal failure, Fanconi's syndrome, nephrogenic diabetic insipidus as reviewed bellow.

\section{Antiretroviral Induced Renal Toxicity}

Regardless of the impact of antiretroviral drugs on ameliorating HIV associated renal disease reports from some 
quarters have associated some antiretroviral agents with renal toxicity. One of the classes of antiretroviral drugs with this attribute is the protease inhibitors with respect to indinavir probably due to volume of reports. One of these reports is a cohort reported by Herman which involved 781 patients exposed to indinavir for a median duration of 53 weeks which revealed an incidence of 7 per 100 persons per year [41]. This is in agreement with the work of Dieleman et al (2002) [42] who in acohort of 1219 involving 644 patients exposed to indinavir reported an incidence of 8.3 per 100/year vs 0.8 per/year for other PIs on renal toxicity while Kopp et al. (2001) [43] reported 3.4\% for indinavir associated renal toxicity. A retrospective analysis of $106 \mathrm{HIV}$ infected patients exposed to indinavir revealed (18.6\%) had sustained elevation of creatinine [44]. This is consistent with18\% (renal failure) reported by Voigt in a study that involved 72 patients exposed to indinavir. Merck and co (1997) reported incidence within the range of $2.6 \%$ - 5\% in 2200 patients and $7 \%$ when doses exceed the recommended clinical dose [45]. An incidence of $8 \%$ out of 240 patients exposed to indinavir was reported by Kopp et al. (1997) [46].

In some studies higher incidence of indinavir associated renal toxicity were reported. One of these studies reported incidence of crystalluria as $67 \%$ which later decreased to $25 \%$ after 2 weeks of therapy in a study which exposed 54 HIV patients to indinavir [47]. An incidence of $23.6 \%$ was reported over 2 years in 555 patients exposed to indinavir [48]. A review of 214 patients on indinavir-containing regimens with a median follow up period of 216 (150 - 312) weeks almost half of the patients had significant loss of renal function that was associated with prolonged use of indinavir. Leukocyturia (51.9\%) was the most common finding of indinavir-associated renal complications [49]. Some authors have equally linked indinavir withacute andchronic renal failure [50-53].

Some studies have shown that atazavavir a member of the PIs family could be associated with renal toxicity but only few cases have reported. This could be buttressed by a retrospective study involving 1,134 patients who received ritonavir-boosted atazanavir and only 11 cases of atazanavir-associated nephrolithiasis were diagnosed [54]. Similarly, 30 cases of atazanavir-induced nephrolithiasis were recorded without chronic renal failure over a four-year study period [55]. Interstitial nephritis with acute renal failure was described in association with atazanavir or atazanavir/tenofovir therapy [56]. Ritonavir is always used as a booster for other protease inhibitors, it is said to have a safe renal profile probably due few reported cases of reversible renal failure and decline in renal function associated with it [57-59]. Other members of the PI family: nelfinavir, imprenavir, fosamprenavir and lopinavir are reported to have good renal profile due low volume of reports or lack of reports [60]. The nonnucleoside reverse transcriptase inhibitors: nevirapine, efavirenze, and delavirdine have safe renal profile as reported [61]. Nevertheless few cases of Fanconis like syndrome and acute renal failure associated with didanosine, stavudine, lamivudine, and abacavir have been reported [62-65].

Another family of antiretroviral drugs that is associated with nephrotoxicity is the nucleotide reverse transcriptase inhibitors family: Adefovir, cidofovir and tenofovir. They differ from the nucleoside reverse transcriptase inhibitors due to the presence of a cyclic mono phosphate component. Cidofovir and adefovir are nephrotoxic, their accumulation in proximal tubular cells and cytotoxicity may cause direct cytotoxic effects on the renal system [66-69]. Adefovir is currently not approved by USA Food and Drug Administration.

\section{Tenofovir Renal Toxicity: Evaluation of Case Reports}

In our previous study we evaluated tenofovir associated renal toxicity with emphasis on cohorts, clinical studies and its reversibility. In this second part emphasis is on the evaluation of individual case reports, implications of drug-drug interactions, involvement of genetic factor and the pharmacology of tenofovir associated renal toxicity. Tenofor is associated with Fanconi's syndrome which results from generalized dysfunction of the proximal renal tubule leading to impaired re absorption of amino acids, glucose, urate, bicarbonate, and phosphate and increased excretion of these solutes into the urine [70]. Fanconi's syndrome can either be inherited or acquired. Inherited forms occur in a number of genetic disorders such as, hereditary, tyrosinemia, hepatorenal, cystinosis, Lowe syndrome, galactosemia, fructose intolerance glycogen storage disease type 1 and Wilson's disease [7176]. It can also be acquired through heavy metal exposure, multiple myeloma, and immunologic disorders [77, 78]. Acquired Fanconi's syndrome has also been associated with the use of a number of medications including aminoglycosides [79]. One of the medications reported to be associated with fanconi's syndrome is tenofovir containing antiretroviral regimens and quite a number of case reports have been documented.

We will start by looking at Kapadia et al. 2013 [80] who presented a case of Fanconi' s syndrome in a HIV patient treated with tenofovir containing antiretroviral regimens characterized by eleveated levels of albuminuria and glycosuria with low serum phosphate level. Another case was presented by Irizarry-Alvarado et al., 2009 [81] in which laboratory results suggested proximal tubular damage consistent with Fanconi’s syndrome due 
to the following manifestations: hyperchloremic, nonanion gap metabolic acidosis; hypouricemia; hypophosphatemia; and normoglycemic glycosuria. Mathew and Knaus reported another case of Fanconis syndrome characterisedby hyperchloremic, non-anion gap metabolic acidosis, hypouricemia, hypophosphatemia and glycosuria. The presence of urine osmolality, polydipsia and polyuria gave credence to nephrogenic diabetes insipidus assumed to be related to tenofovir use [82]. Some scholars presented 7 cases of renal injury associated with tenofovir therapy which are consistent with Fanconi's syndrome. Observations revealed proximal renal tubular acidosis, normoglycemic glycosuria, hematuria, hypophosphatemia, hypouricemia, hypokalemia, aminoaciduria, citrullinuria and proteinuria. In one of these cases renal biopsy revealed tubulointerstitial nephropathy with primary lymphocytic infiltrate [83].

Another study presented a HIV patient who was intolerant to some antiretroviral drugs and had persistent virological failure was placed on a new therapeutic regimen containing tenofovir, guided by resistance testing. Due to patient's case presentation, laboratory analysis showed hyperlactatemia, metabolic acidosis, proteinuria, glucosuria, aminoaciduria and elevated serum creatinine which is suggestive of Fanconi's syndrome [84]. Another case of tenofovir induced Fanconi's syndrome in a HIV patient was reported by creput and colleagues. Fanconi's syndrome was diagnosed on the basis of the presence of metabolic acidosis, glycosuria, phosphaturia, proteinuria and hypouricemia. Urinary cytology revealed large amounts of desquamated cells of apparent tubular origin at various stages of degeneration, varying from cells with pyknotic nuclei to anucleate cells and cytoplasmic fragments. There were also rare clusters of mildly atypical squamous cells, and no evidence of crystals. Renal biopsy revealed lesions that were largely localized in the proximal convoluted tubules. There was generalized necrosis and sloughing of tubular cells, with denuding of the tubular basement membrane. When present, the tubular cell cytoplasm appeared thin and often vacuolated. Surrounding the tubules was focal interstitial inflammation of mixed character, without significant destruction of tubular basement membranes [85].

Some case reports showed that tenofovir could induce renal failure and Fanconi's syndrome simultaneously. One of these case reports was reported by Olea and others in a patient on TDF/LOP-RTV containing regimens. Laboratory evaluation revealed glycosuria, aminoaciduria, hyperuricosuria, protenuria, hypercalciuria. This was supported by renal biopsy which revealed acute focal tubule interstitial nephritis with focal tubular atrophy and necrosis [86]. Similar observation was reported by Kapitsinou and Ansari who presented a case of a HIV patient on tenofovir containing antiretroviral regimen who developed acute renal failure and fanconis syndrome characterized by severe metabolic acidosis and acretinine clearance of $9.8 \mathrm{mg} / \mathrm{dl}$ [87].

Schaaf and co in 2003 [88] also reported a case of renal failure a HIV patient switched to 3TC/d4T/TDF/LOPRTV from an initial antiretroviral regimen due to lack of adherence and virological failure. Biochemical evaluation revealed impaired biomarkers of renal function. Renal biopsy showed a mild interstitial infiltrate consisting of lymphocytes, focal atrophic changes in cortical tubules, luminal ectasia and loss of brush border in tubules. The authors attributed this renal failure to tenofovir but could there be potentiation of acute renal failure by lopinavir-rotinavir due to reported cases of nephrotoxicity by these agents.

Patel et al. 2007 [89] added their voices by reporting a case of renal failure in HIV positive patient who was treated with some antiretroviral drugs but later switched to 3TC/EFV/TDF. Biochemical evaluation revealed imbalance in renal biochemical parameters which was attributed to tenofovir. Renal biopsy showed sclerosed glomeruli with ischemic injury including portal collapse of the capillary loops. Histopathological changes in glomeruli include mild mesangial proliferation, increased mesangial matrix and thickened capillary loops. Moderate degenerative tubular changes, loss of tubular mass, interstitial scarring and scattered cellular infiltrates were observed. This observation is similar to the work of Lee et al. [90] entitled acute tubular necrosis in a patient receiving tenofovir. Collectively they reported tenofovir attributed renal impairment associated with increase cretinine clearance. They further supported their work by a confirmatory renal biopsy which revealed severe tubular necrosis with mild degree of interstitial fibrosis and patchy mild tubular atrophy. In 2006 Zimmermann and co workers [91] reported five cases of HIV positive patient with acute renal failure and Fanconi's syndrome associated with tenofovir containing antiretroviral regimens. In these patients acute tubular necrosis was identified by urinary sediment with pigmented granular casts. Renal biopsy revealed unique lesions due to karyomegaly in proximal tubular nuclei. Similar incidence of tenofovir associated Fanconi's syndrome, nephrogenic diabetes insipidus, and acute renal failure was reported by Verhelst et al., 2002 [92].

Karas and colleague reported 3 cases of renal toxicity associated with tenofovir. Renal failure, proximal tubular dysfunction and nephrogenic diabetes insipidus were observed. In 2 of the 3 cases, renal biopsy revealed severe tubular necrosis with characteristic nuclear changes [93]. Another episode of acute renal failure in collaboration with Fanconis's syndrome was made public by Gaspar and friends. Their observation was characterized by glucosuria, aminoaciduria, phosphaturia, calciuria and 
uricosuria, hyperchoremic metabolic acidosis and hypokalemia [94]. This observation is in agreement with reports of similar incidence by some authors [95-97].

\section{Implications of Drug-Drug Interactions in Tenofovir Renal Toxicity}

Drugs are been co administered to increase pharmacological or therapeutic benefits which has been proven in human and animal studies. It is also known that combined use of multiple drugs may cause toxicological effects as a result of drug-drug interactions which could be pharmacodynamic or pharmacokinetic interactions [98]. Antiretroviral regimens contain 3 - 4 drugs which could be administered with other drugs in the presence of co morbidity. There are reported cases of interactions involving antiretroviral drugs and other drugs and one of these interactions is with non steroidal anti-inflammatory drugs (NSAIDs). Cases of renal failure associated with Fanconi's syndrome in HIV patients on tenofovir containing antiretroviral drugs and NSAIDs have been reported [99]. Bicket and colleague reported that drug-drug interaction involving diclofenac could exacerbate tenofovir acute kidney injury. They drew their conclusion from a cohort involving 89 patients on diclofenac of which 61 patients were treated with tenofovir. They observed that 13 patients (14.6\%) developed renal impairment [100]. This is in agreement with reports from some quarters on NSAIDS induced renal toxicity in humans [101-105]. In animal studies NSAIDs associated nephrotoxicity was characterized by glomerular degeneration, tubular necrosis, mild interstitial inflammation, glomerulo-nephritis with several proximal convoluted tubules having attenuated and necrotic epithelium. These NSAIDs induced morphological changes are similar to reported tenofovir induced renal changes in animals [106110]. It was also reported that incidence of acute renal failure associated with NSAIDS account for $15.5 \%$ of all cases of drug induced acute renal failure hence combination of tenofovir with other drugs with nephrotoxic potentials should be avoided [111]. Another case of drugdrug interaction that could induce additive, synergistic or potentiate nephrotoxicity is between antiretroviral drugs and aminoglycoside class of antibiotics. HIV is always associated with co morbidity like tuberculosis that may require co administration of antiretrovirals and aminoglycosides. Recent report showed that tenofovir/streptomycin and tenofovir/ kinamycin induced renal toxicity in HIV patients with tuberculosis [112]. Aminoglycosides antibiotics are known to be associated with renal toxicity. Some scholars have reported an incidence of $20 \%$ - 50\% for aminoglycoside associated renal toxicity $[113,114]$. In humans aminoglycoside can alter the function and architecture of the kidney [115-118]. In animal studies aminiglycosides induced renal histopathological changes was characterised by glomerular congestion, glomerular degeneration, loss of bowman's capsule space, necrotic changes inform of pale cytoplasm, pkynosis, karyolysis and cellular infiltration in the cortex. Other histopathological changes include basal membrane interruption, mesangial proliferation and apoptosis, indicated by decreases in glomerular filtration and alteration in intraglomerular dynamics [119-121]. Despite few reported cases the co administration of tenofovir and aminiglycosides should be done with caution especially in patients with HIV induced tuberculosis. It is biologically possible that aminoglycosides and tenofovir associated nephrotoxicity may be synergistic in the mitochondria of proximal tubular cells, one suggestive clinical approach is that the combination could be used, but with close monitoring of renal function parameters.

Furthermore synergistic or additive nephrotoxicity can arise from antiretroviral-antiretroviral interactions. One of the suspected interactions is between tenofovir and the protease inhibitors family. Some scholars observed that most patients who developed nephrotoxicity associated with tenofovir received protease inhibitors [122]. In the early part of this study we vividly explain protease inhibitors associated nephrotoxicity with more tribute to indinavir due to available literature. The treatment guideline for HIV management allows the co administration of tenofovir and boosted indinavir [123]. Only few cases of atazanavir induced renal toxicity have been reported as earlier explain in our work but in vitro studies, have shown that atazanavir is an inhibitor and inducer of P-glycoprotein and an inhibitor of cytochrome P450 3A activity. This may potentiate the pharmacological profile of some drugs [124]. This can be supported by a report which showed that coadministration of tenofovir with atazanavir could increase the pharmacokinetic parameters of tenofovir and requires patient monitoring [125, 126]. In June 2004, Gilead revised the package insert to include monitoring for adverse effects in patients receiving tenofovir in combination with atazanavir or lopinavir-ritonavir associated with increased tenofovir concentrations, as well as the potential for the development of ARF and Fanconi syndrome.

Didanosine is said to be associated with renal toxicity, an early case report by Crowther et al. 1993 [127] described didanosine induced Fanconi's syndrome and nephrogenic diabetes insipidus. Some scholars also have attributed antiretroviral induced renal toxicity to didanosine [128]. Didanosine has been clinically used with tenofovir and there are reported cases of renal toxicity attributed to their co administration [129-131]. Literature showed that coadministration of tenofovir and didanosine have resulted in a significant increase (28\%) in maximum serum concentrations of didanosine, leading to an 
increased risk of didanosine toxicity [132]. Didanosine is taken up by hOAT1 at the proximal tubules, and it is possible that competition between tenofovir and didanosine for the hOAT1 transporter produces an increase in the didanosine concentration, leading to an increased risk of mitochondrial damage and nephropathy.

In vitro experiments in renal proximal tubule cells have recently shown that didanosine may be very toxic and had negative effects on mitochondrial DNA and cytochrome oxidase II mRNA. This effect was enhanced in the presence of tenofovir, suggesting that didanosine cellular clearance was inhibited [133,134]. Moreover, administration of didanosine to patients also receiving tenofovir may increase the risk of tenofovir-associated proximal tubulopathy and nephrogenic diabetes.

\section{Impact of Genetic Polymorphism on Tenofovir Renal Toxicity}

TFV-associated kidney tubular damage (KTD) is multifactorial with risk factors including polymorphisms along with nongenetic factors, such as age, and body weight $[135,136]$. One of these risk factors that have captured attention is the genetic factor which must have introduced dichotomy in the distribution of HIV associated renal damage between the black and the white population.Reports have shown incidence of higher HIV associated renal damage especially HIVN among AfricanAmericans while higher incidence of immune complexmediated glomerulonephritis occurred among the whites. This is supported with Data from the US Renal Database System (USRDS) which revealed that renal disease attributed to HIVAN recorded in the US nearly 90\% are reported in African-Americans [137]. This is consistent with another report from the Veterans Affairs Medical System which showed a higher incidence of end-stage renal disease among HIV-infected African-Americans which may suggests genetic predisposition in HIV associated renal disease [138]. A similar incidence of higher end- stage renal disease in blacks was also reported in a single-center study from Johns Hopkins, with an 18-fold higher risk for progression to ESRD among HIV infected African-Americans compared with HIV-infected Caucasians [139]. The genetic basis of this disparity was further elucidated by Rodrigues-Nova and co who explored the association between kidney tubular dysfunction and polymorphisms in genes encoding drug transporters. They reported that approximately $17 \%$ of HIV-infected patients treated with tenofovir had kidney tubular dysfunction homozygosity for the $C$ allele at position -24 of the $A B C C 2$ gene which is strongly associated with KTD in this population. This polymorphism may help to identify patients at greater risk for developing tenofovir-associated tubulopathy, and close monitoring of renal function is warranted for these patients [140]. Similar observation was reported by Izzedine et al. who assess the influence of single-nucleotide polymorphisms (SNPs) identified in $A B C C 2$ and $A B C C 4$. They were able to observethat ABCC2 haplotypes are associated with rPT induced by TDF in HIV-1-infected patients. No association was observed between ABCC4 polymorphism and TDF-induced rPT in the present study [141].

Pushpakom et al. also explored the association of $A B C C 10$ transports and $A B C C 10$ single-nucleotide polymorphisms (SNPs) with tenofovir induce KTD. They reported that tenofovir is a substrate for $A B C C 10$, and genetic variability within the $A B C C 10$ gene may influence tenofovir renal tubular transport and contribute to the development of KTD [142]. The association between tenofovir-induced KTD and 14 single nucleotide polymorphisms (SNPs) in the $A B C C 2, A B C C 4, A B C C 10$, SCL22A6, and $A B C B 1$ genes was investigated in 190 Japanese patients, by Nishijima et al., [143] in this study they acknowledge the association between SNPs in ABCC2 and tenofovir-induced KTD in an Asian population. These reports leave more rooms for questions, do the African-American population habour genetic polymorphism that is vulnerable or predispose to tenofovir associated renal damage? This calls for more evaluations.

\section{Possible Pharmacology of Tenofovir Renal Toxicity}

The mechanisms of drug induced renal toxicity can vary largely based on the pharmacologic action, metabolism, and ultimate pathway of excretion of the administered drug. Although several recent studies have revealed the nephrotoxicity of tenofovir, but the mechanism of tenofovir nephrotoxicity is not clear. Studies have suggested that mitochondrial damage may play an important role in TDF induced renal damage [144].

Researchers have shown that tenofovir is eliminated in the kidney by glomerular filtration and tubular secretion. Circulating tenofovir is absorbed from the bloodstream into the proximal tubule cells by the renal organic anion transporters (hOATs) 1 and 3. Efflux from these cells into the tubular lumen is mediated by the multidrug resistance protein (MDR)-4 [145]. The hOATs may generate high intratubular tenofovir concentrations that may interfere with the replication of mitochondrial DNA [146]. Interference with the function of mitochondria can be supported by some animal studies in which administration of TDF $100 \mathrm{mg} / \mathrm{kg} /$ day revealed enlargement of mitochondria and disruption of mitochondria crystal in rats [147]. A study in which HIV + transgenic mice and their wild-type littermates were exposed to tenofovir, renal proximal tubules showed ultrastructural mitochondrial abnormalities and decreased mtDNA levels, which 
paralleled the ultrastructural mitochondrial abnormalities [148]. Similar observation was reported when Rats were exposed to tenofovir, proximal tubular dilatation, abnormalities in mitochondrial ultrastructure, depleted mtDNA, and depressed respiratory chain enzyme expression (cytochrome $c$ oxidase and nicotinamide adenyldinucleotide dehydrogenase) were noted [149].

It is well known that mitochondria are the primary intracellular sources of reactive oxygen species (ROS), as they generate huge numbers of oxidative-reduction reactions and use massive amounts of oxygen [150-152]. Mitochondria damage by tenofovir can stimulate ROS production like superoxide anion, hydrogen peroxide, and hydroxyl radical which can results in oxidative stress in the kidney. Oxidative stress can lead to the destruction of biomolecules such as DNA, proteins, and lipids, thus leading to the accumulation of oxidative damaged products within the cell, causing the deregulation of redoxsensitive metabolic, signaling pathways, and cell death. The activity of tenofovir in the kidney can also deplete the following antioxidants glutathione and antioxidant enzymes such as superoxide dismutases, catalase, glutathione peroxidase, glutathione reductase and glutathione S transferase as observed in some drugs [153-155]. The decrease in the antioxidant system in cells can increase susceptibility of cells to the toxicological effect of ROS resulting in oxidative stress. Thus, oxidative stress can result from overproduction of ROS and/decrease in the antioxidant system in cells.

The above explained mechanism is in agreement with an animal study in which rats were administered by gavage $600 \mathrm{mg} / \mathrm{kg}$ body weight tenofovir disoproxil fumarate for 35 days. Tenofovir administration to rats resulted in glomerular and tubular damage. Evaluation with Electron microscope revealed mitochondrial swelling, disruption of cristae and accumulation of amorphous deposits in the matrix. Significant increase in protein carbonyl content, decrease in reduced glutathione and protein thiol, decrease in the activities of the antioxidant enzymes such as superoxide dismutase, glutathione peroxidase, glutathione $\mathrm{S}$ transferase and glutathione reductase and a massive increase in myeloperoxidase activity was observed in the kidneys of tenofovir treated rats [155].

\section{Conclusion}

Despite tenofovir reported renal toxicity; it has achieved a very high and notable clinical success in the management of HIV/AIDS. But renal function status of HIV positive patients should be ascertained and other risk factors ruled out before tenofovir administration. Biomarkers of renal function should be routinely evaluated in patients on tenofovir containing antiretroviral regimens. Co administration with potential nephrotoxic drugs should be avoided except when benefit outweighs risk.

\section{REFERENCES}

[1] "Principles and Methods for the Assessment of Nephrotoxicity Associated with Exposure to Chemicals," International Programme on Chemical Safety (IPCS), World Health Organization, Geneva, 1991.

[2] N. Anzai and H. Endou, "Drug Transport in the Kidney, in Drug Transporters Molecular Characterization and Role in Drug Disposition,” John Wiley \& Sons, Inc., New Jersey, 2007, pp. 463-493.

[3] N. Anzai and H. Endou, "Renal Drug Transporters and Nephrotoxicity," Proceedings of 6th World Congress on Alternatives \& Animal Use in the Life Sciences, 21-25 August 2007, Tokyo, AATEX 14, Special Issue, pp. 447452.

[4] T. Cihlar, E. S. Ho, D. C. Lin and A. S. Mulato, "Human Renal Organic Anion Transporter 1 (hOAT1) and Its Role in the Nephrotoxicity of Antiviral Nucleotide Analogs," Nucleosides, Nucleotides and Nucleic Acids, Vol. 20, No. 4-7, 2001, pp. 641-648. http://dx.doi.org/10.1128/AAC.00251-06

[5] A. S. Ray, T. Cihlar, K. L. Robinson, et al., "Mechanism of Active Renal Tubular Efflux of Tenofovir," Antimicrobial Agents and Chemotherapy, Vol. 50, No. 10, 2006, pp. 3297-3304. http://dx.doi.org/10.1128/AAC.00251-06

[6] S. Rodriguez-Nvoa, E. Alvarez, P. Labarga and V. Soriano, "Renal Toxicity Associated with Tenofovir Use," Expert Opinion on Drug Safety, Vol. 9, No. 4, 2010, pp. 545-559. http://dx.doi.org/10.1517/14740331003627458

[7] B. Fernandez-Fernandez, A. Montoya-Ferrer, A. B. Sanz, M. D. Sanchez-Nino and M. C. Izquierdo, "Tenofovir Nephrotoxicity: Update,” AIDS Research and Treatment, Vol. 2011, 2011, pp. 1-11. http://dx.doi.org/10.1155/2011/354908

[8] B. S. Rifkin and M. A. Perazella, "Tenofovir-Associated Nephrotoxicity: Fanconi Syndrome and Renal Failure,” American Journal of Medicine, Vol. 117, No. 4, 2004, pp. 282-284. http://dx.doi.org/10.1016/j.amjmed.2004.03.025

[9] S. Coca and M. A. Perazella, "Acute Renal Failure Associated with Tenofovir: Evidence of Drug-Induced Nephrotoxicity," American Journal of Medical Science, Vol. 324, No. 6, 2002, pp. 342-344. http://dx.doi.org/10.1038/ki.2010.318

[10] L. C. Herlitz, S. Mohan, M. B. Stokes, J. Radhakrishnan, V. D. D’Agati and G. S. Markowitz, “Tenofovir Nephrotoxicity: Acute Tubular Necrosis with Distinctive Clinical, Pathological, and Mitochondrial Abnormalities,” Kidney International, Vol. 78, No. 11, 2010, pp. 1171-1177. http://dx.doi.org/10.1038/ki.2010.318

[11] M. A. Perazella, “Tenofovir-Induced Kidney Disease an Acguired Renal Tubular Mitochondriopathy,” Kidney International, Vol. 78, 2010, pp. 1060-1063. http://dx.doi.org/10.1038/ki.2010.344

[12] E. Daugas, J. P. Rougier and G. Hill, "HAART-Related Nephropathies in HIV-Infected Patients,” Kidney International, Vol. 67, 2005, pp. 393-403. http://dx.doi.org/10.1111/j.1523-1755.2005.67096.x

[13] J. J. Bourgoignie, R. Meneses, C. Ortiz, D. Jaffe and V. Pardo, "The Clinical Spectrum of Renal Disease Asso- 
ciated with Human Immunodeficiency Virus,” American Journal of Kidney Disease, Vol. 12, No. 2, 1998, pp. 131137.

[14] A. Laradi, A. Mallet, H. Beaufils, M. Allouache and F. Martinez, "HIV Associated Nephropathy: Outcome and Prognosis Factors. Groupe d'Etudes Nephrologiques d'Ile de France," Journal of American Society of Nephrology, Vol. 9, No. 12, 1998, pp. 2327-2335.

[15] T. S. Ahuja, M. Borucki, M. Funtanilla, V. Shahinian, M. Hollander and S. Rajaraman, "Is the Prevalence of HIVAssociated Nephropathy Decreasing?” American Journal of Nephrology, Vol. 19, 1999, pp. 655-659. http://dx.doi.org/10.1159/000013537

[16] M. J. Ross, L. A. Bruggeman, P. D. Wilson and P. E. Klotman, "Microcyst Formation and HIV-1 Gene Expression Occur in Multiple Nephron Segments in HIV-Associated Nephropathy," Journal of American Society of Nephrology, Vol. 12, No. 12, 2001, pp. 2645-2651.

[17] D. Marras, L. A. Bruggeman, F. Gao, et al, "Replication and Compartmentalization of HIV-1 in Kidney Epithelium of Patients with HIV Associated Nephropathy," Nature Medicine, Vol. 8, No. 5, 2002, pp. 522-526.

[18] P. L. Kimmel, L. Barisoni and J. B. Kopp, "Pathogenesis and Treatment of HIV Associated Renal Diseases: Lessons from Clinical and Animal Studies, Molecular Pathologic Correlations, and Genetic Investigations,” Annals of Internal Medicine, Vol. 139, No. 3, 2003, pp. 214-227. http://dx.doi.org/10.7326/0003-4819-139-3-200308050-0 $\underline{0019}$

[19] S. Casanova, G. Mazzucco, G. Barbiano di Belgiojoso, et al., "Pattern of Glomerular Involvement in Human Immunodeficiency Virus-Infected Patients: An Italian Study," American Journal of Kidney Disease Vol. 26, No. 3, 1995, pp. 446-453. http://dx.doi.org/10.1016/0272-6386(95)90490-5

[20] R. V. Boccia, E. P. Gelmann, C. C. Baker, G. Marti and D. L. Longo, "A Hemolyticuremic Syndrome with the Acquired Immunodeficiency Syndrome," Annals of Internal Medicine, Vol. 101, No. 5, 1984, pp. 716-717. http://dx.doi.org/10.7326/0003-4819-101-5-716_2

[21] J. Cuttner, "Thrombotic Thrombocytopenic Purpura: A Ten Year Experience,” Blood, Vol. 56, No. 2, 1908, pp. 302-306.

[22] R. M. Petitt, “Thrombotic Thrombocytopenic Purpura: A Thirty Year Review," Seminars in Thrombosis and $\mathrm{He}$ mostasis, Vol. 6, No. 4, 1980, pp. 350-355. http://dx.doi.org/10.1055/s-2007-1005108

[23] T. J. Torok, R. C. Holman and T. L. Chorba, "Increasing Mortality from Thrombotic Thrombocytopenic Purpura in the United States. Analysis of National Mortality Data, 1968-1991," American Journal of Hematology, Vol. 50, No. 2, 1995, pp. 84-90. http://dx.doi.org/10.1002/ajh.2830500203

[24] M. Noris and G. Remuzzi, "Atypical Hemolytic-Uremic Syndrome,” New England Journal of Medicine, Vol. 361, 2009, pp. 1676-1687. http://dx.doi.org/10.1056/NEJMra0902814

[25] A. C. Alpers, "Light at the End of the TUNEL: HIVAssociated Thrombotic Microangiopathy,” Kidney Inter- national, Vol. 63, 2003, pp. 385-396.

http://dx.doi.org/10.1046/j.1523-1755.2003.00743.x

[26] J. S. Berns, "Haemolytic Uraemic Syndrome and Thrombotic Thrombocytopenic Purpura Associated with HIV Infection, in Renal and Urologic Aspects of HIV Infection,” Churchill Livingstone, New York, 1995, pp. 111134.

[27] P. Coppo and A. Veyradier, "Thrombotic Microangiopathies: Towards a Pathophysiology-Based ClassificationCardiovascular \& Haematological Disorders,” Drug Targets, Vol. 9, No. 1, 2009, pp. 36-50.

[28] M. C. Wyatt and P. E. Klotman, "HIV-1 and HIV-Associated Nephropathy 25 Years Later,” Clinical Journal of American Society of Nephrology, Vol. 2, Suppl. 1, 2007, pp. 20-24. http://dx.doi.org/10.2215/CJN.03561006

[29] E. J. Schwartz, L. A. Szczech, M. J. Ross, M. E. Klotman, et al., "HAART and the Epidemic of HIV End Stage Renal Disease," Journal of American Society of Nephrology, Vol. 16, No. 8, 2005, pp. 2412-2420. http://dx.doi.org/10.1681/ASN.2005040340

[30] R. K. Wali, C. I. Drachenberg, J. C. Papadimitriou, S. Keay and E. Ramos, "HIV-1-Associated Nephropathy and Response to Highly-Active Antiretroviral Therapy,” Lancet, Vol. 352, No. 9130, 1998, pp. 783-784. http://dx.doi.org/10.1016/S0140-6736(98)24037-2

[31] J. A. Winston, L. A. Bruggeman, M. D. Ross, J. Jacobson and J. Ross, "Nephropathy and Establishment of a Renal Reservoir of HIV Type 1 during Primary Infection,” New England Journal of Medicine, Vol. 344, 2001, pp. 19791984. http://dx.doi.org/10.1056/NEJM200106283442604

[32] L. A. Szczech, L. J. Edwards, L. L. Sanders, C. van der Horst, et al., "Protease Inhibitors Are Associated with a Slowed Progression of HIV-Related Renal Diseases," Clinical Nephrology, Vol. 57, 2002, pp. 336-341. http://dx.doi.org/10.5414/CNP57336

[33] C. J. Cosgrove, A. K. Abu-Alfa and M. A. Perezella, "Observations on HIV Associated Renal Diseases in the Era of Highly Active Antiretroviral Therapy,” American Journal of Medical Sciences, Vol. 323, No. 2, 2002, pp. 102-106. http://dx.doi.org/10.1097/00000441-200202000-00009

[34] A. Reid, W. Stohr, S. Walker, F. Ssali, P. Munderi and C. Gilks, (on Behalf of the DART Trial), "Glomerular Dysfunction and Associated Risk Factors Following Initiation of ART in Adults with HIV Infection in Africa," XVI International AIDS Conference, Toronto, 13-18 August 2006.

[35] C. Burckle, J. Medioni, D. Nochy, et al., "HIV-Associated Nephropathy: Outcome and Prognosis Factors since the Introduction of Highly Active Antiretroviral Therapy-GENIF," Journal of American Society Nephrology, Vol. 13, 2002, p. 381A.

[36] M. G. Atta, J. E. Gallant, M. H. Rahman, N. Nagajothi, L. C. Racusen, P. J. Scheel and D. M. Fine, "Antiretroviral Therapy in the Treatment of HIV-Associated Nephropathy,” Nephrology Dialysis Transplantation, Vol. 21, No. 10, 2006, pp. 2809-2813. http://dx.doi.org/10.1093/ndt/gfl337

[37] J. J. Scialla, M. G. Atta and D. M. Fine, "Relapse of HIV- 
Associated Nephropathy after Discontinuing Highly Active Antiretroviral Therapy,” AIDS, Vol. 21, No. 2, 2007, pp. 263-264.

http://dx.doi.org/10.1097/QAD.0b013e3280119592

[38] G. M. Lucas, J. A. Eustace, S. Sozio, E. K. Mentari, K. A. Appiah and R. D. Moore, "Highly Active Antiretroviral Therapy and the Incidence of HIV-1-Associated Nephropathy: A 12-Year Cohort Study,” AIDS, Vol. 18, No. 3, 2004, pp. 541-546.

http://dx.doi.org/10.1097/00002030-200402200-00022

[39] B. Murphy, L. Carlson, S. Rohal, M. Keller, A. Lu, M. S. A. Kumar, et al., "Renal Transplantation in HIV-Infected Recipients: Twenty-Three Cases in the HAART Era," Journal of American Society of Nephrology, Vol. 13, 2002, p. 11A.

[40] J. T. Kircher, "Resolution of Renal Failure after Initiation of HAART, 3 Cases and a Discussion of the Literature," AIDS Read, Vol. 12, No. 3, 2002, pp. 103-105,110-112.

[41] J. S. Herman, N. J. Ives, M. Nelson, B. G. Gazzard and P. J. Easterbook, "Incidence and Risk Factor for Development of Indinavir-Associated Renal Implications,” Journal of Antimicrobial Chemotherapy, Vol. 48, No. 3, 2001, pp. 355-360. http://dx.doi.org/10.1093/jac/48.3.355

[42] J. P. Dieleman, M. C. Sturkenboom, M. Jambroes, I. C. Gyssens, G.-J. Weverling, J. H. ten Veen, G. Schrey, P. Reiss and B. H. Ch. Stricker, "Risk Factor for Urological Symptoms in a Cohort of Users of HIV Protease Inhibitors Indinavir Sulphate the ATHENA Cohort," JAMA Internal Medicine, Vol. 162, No. 13, 2002, pp. 1493-1501. http://dx.doi.org/10.1001/archinte.162.13.1493

[43] J. B. Kopp, K. D. Miller A. J. Mican, et al., "Urinary Stones in HIV-1-Positive Patients Treated with Indinavir," Lancet, Vol. 349, No. 9061, 1294, pp. 1294-1295.

[44] K. Boubaker, P. Sudre, F. Bally, G. Vogel, J. Y. Meuwly, M. P. Glauser, et al., "Changes in Renal Function Associated with Indinavir,” AIDS, Vol. 12, 1998, pp. 249-254.

[45] Merck and Co, "Crixivan (Indinavir Sulphate) Product Monograph,” Merk and Co, West Point, 1997.

[46] J. B. Kopp, K. D. Miller, J. A. Milan, I. M. Feuerstein, E. Vaughan, C. Baker, L. K. Pannell and J. Falloon, "Crystalluria and Urinary Tract Abnormalities Associated with Indinavir,” Annals of Internal Medicine, Vol. 127, No. 2, 1997, pp. 119-125.

http://dx.doi.org/10.7326/0003-4819-127-2-199707150-0 $\underline{0004}$

[47] R. F. Gangnon, S. N. Tecimer, A. K. Waters and C. M. Tsoukas, "Prospective Study of Urinalysis Abnormalities in HIV-Positive Individuals Treated with Indinavir," American Journal of Kidney Disease, Vol. 36, No. 3, 2000, pp. 507-515. http://dx.doi.org/10.1053/ajkd.2000.9791

[48] P. Meravigla, E. Angeli, F. Del Sorbo, G. Rombolà, P. Viganò, G. Orlando, L. Cordier, I. Faggion and A. Cargnel, "Risk Factors for Indinavir-Related Renal Colic in HIV Patients: Predictive Value of Indinavir Dose/Body Mass Index,” AIDS, Vol. 16, No. 15, 2002, pp. 2089-2093. http://dx.doi.org/10.1097/00002030-200210180-00019

[49] A. Avihingsanon, Y. Avihingsanon, P. Darnpornprasert, S. Kerr and C. Ungsedhapand, C. Duncombe, S. Ubolyam, K. Ruxrungtham and P. Phanuphak, "High Prevalence of
Indinavir-Associated Renal Complications in Thai HIVInfected Patients," Journal of Medical Association of Thailand, Vol. 89, No. 2, 2006, pp. S21-S27.

[50] M. Jaradat, C. Philips, M. N. Yum, H. Cushing and S. Moe, "Acute Tubuloinsterstitial Nephritis Attributed to Indinavir Therapy," American Journal of Kidney Disease, Vol. 35, No. 4, 2000, p. E16. http://dx.doi.org/10.1016/S0272-6386(00)70034-5

[51] A. M. Van Rossum, J. P. Dieleman and P. L. Fraaij, K. Cransberg, N. G. Hartwig, D. M. Burger, I. C. Gyssens and R. de Groot, "Persistent Sterile Leukocyturia Is Associated with Impaired Renal Function inHuman Immunodeficiency Virus Type 1-Infected Children Treated With Indinavir," Pediatrics, Vol. 110, No. 2, 2002, p. e19.

[52] M. Daudon, L. Estepa, J. P. Viard, D. Joly and P. Jungers, "Urinary Stones in HIV-1-Positive Patient Treated with Indinavir,” Lancet, Vol. 349, No. 9061, 1997, pp. 12941295. http://dx.doi.org/10.1016/S0140-6736(05)62506-8

[53] H. Hanabusa, H. Tagami and H. Hataya, "Renal Atrophy Associated with Long-Term Treatment with Indinavir," New England Journal of Medicine, Vol. 340, 1999, pp. 392-393. http://dx.doi.org/10.1056/NEJM199902043400515

[54] U. C. Brewster and M. A. Perazella, "Acute Interstitial Nephritis Associated with Atazanavir, a New Protease Inhibitor," American Journal of Kidney Disease, Vol. 44, No. 5, 2004, pp. e81-e84.

[55] S. Schmid, M. Opravil, M. Moddel, M. Huber, R. Pfammatter, G. Keusch, P. Ambuhl, R. P. Wuthrich, H. Moch and Z. Varga, "Acute Interstitial Nephritis of HIV Positive Patients under Atazanavir and Tenofovir Therapy in a Retrospective Analysis of Kidney Biopsies," Virchows Archiv, Vol. 450, No. 6, 2007, pp. 665-670. http://dx.doi.org/10.1007/s00428-007-0418-3

[56] K. Chan-Tack, M. Truffa, K. Struble and D. Birnkrant, "Atazanavir-Associated Nephrolithiasis: Cases from the US Food and Drug Administration's Event Reporting System,” AIDS, Vol. 21, No. 9, 2007, pp. 1215-1218. http://dx.doi.org/10.1097/QAD.0b013e32813aee35

[57] S. Chugh, R. Bird and E. A. Alexander, "Ritonavir and Renal Failure,” New England Journal of Medicine, Vol. 336, 1997, p. 138. http://dx.doi.org/10.1056/NEJM199701093360214

[58] M. V. Bochet, C. Jacquiaud, M. A. Valantin, C. Katlama and G. Deray, "Renal Insufficiency Induced by Ritonavir in HIV-Infected Patients,” American Journal of Medicine, Vol. 105, No. 5, 1998, p. 457.

[59] M. Duong, C. Sgro, M. Grappin, F. Biron and A. Boibieux, "Renal Failure after Treatment with Ritonavir," Lancet, Vol. 348, No. 9028, 1996, p. 693. http://dx.doi.org/10.1016/S0140-6736(05)65125-2

[60] J. Roling, H. Schmid, M. Fischereder, R. Draenert and F. D. Goebel, "HIV-Associated Renal Diseases and Highly Active Antiretroviral Therapy-Induced Nephropathy," Clinical Infectious Diseases, Vol. 42, No. 10, 2006, pp. 1488-1495. http://dx.doi.org/10.1086/503566

[61] A. Angel-Moreno-Maroto, L. Suarez-Castellano, M. Hernandez-Cabrera and J. L. Perez-Arellano, "Severe Efavirenz-Induced Hypersensitivity Syndrome (not-DRESS) with 
Acute Renal Failure,” Journal of Infectious, Vol. 52, No. 2, 2006, pp. e39-e40.

http://dx.doi.org/10.1016/j.jinf.2005.05.020

[62] H. Izzedine, V. Launay-Vacher and G. Deray, "Fanconi Syndrome Associated with Didanosine Therapy," AIDS, Vol. 19, No. 8, 2005, pp. 844-845.

http://dx.doi.org/10.1097/01.aids.0000168985.05209.b8

[63] "International Agency for Research on Cancer (IARC) Monographs on the Evaluation of Carcinogenic Risks to Humans, Some Antiviral and Antineoplastic Drugs, and Other Pharmaceutical Agents," International Agency for Research on Cancer Scientific Publication, Vol. 76, 2000.

[64] A. A. Morris, S. V. Baudouin and M. H. Snow, "Renal Tubular Acidosis and Hypophosphataemia after Treatment with Nucleoside Reverse Transcriptase Inhibitors,” AIDS, Vol. 15, No. 1, 2001, pp. 140-141. http://dx.doi.org/10.1097/00002030-200101050-00027

[65] M. Krishnan, R. Nair, M. Haas and M. G. Atta, "Acute Renal Failure in an HIV-Positive 50-Year-Old Man," American Journal of Kidney Disease, Vol. 36, No. 5, 2000, pp. 1075-1078. http://dx.doi.org/10.1053/ajkd.2000.19114

[66] H. O. Es, D. C. Lin, D. B. Mendel and T. Cihar, "Cytotoxicity of Antiviral Nucleotide Adefovir and Cidofovir Is Induced by Expression of Human Renal Organ Anion Transporter," Journal of the American Society of Nephrology, Vol. 11, No. 3, 2000, pp. 383-393.

[67] P. Meier, S. Dautheville-Guibal, P. M. Ronco and J. Rossert, "Cidofovir Induced End Stage Renal Failure," $\mathrm{Ne}$ phrology Dialysis Transplantation, Vol. 17, No. 1, 2002, pp. 148-149. http://dx.doi.org/10.1093/ndt/17.1.148

[68] N. Tanji, K. Tanji, N. Kambham, G. S. Markowitz, A. Bell and V. D. D’Agati, “Adefovir Nephrotoxicity: Possible Role of Mitochondria DNA Depletion,” Human Pathology, Vol. 32, No. 7, 2001, pp. 734-740. http://dx.doi.org/10.1053/hupa.2001.25586

[69] K. C. Cundy, "Clinical Pharmacokinetics of Antiviral Nucleotides Adefovir and Cidofovir," Clinical Pharmacokinetics,” Vol. 36, No. 2, 1999, pp. 127-143. http://dx.doi.org/10.2165/00003088-199936020-00004

[70] K. E. Earle, T. Seneviratne, J. Shaker and D. Sboback, "Fanconi's Syndrome in HIV1 Adults: Report of Three Cases and Literature Review,” Journal of Bone and Mineral Research, Vol. 19, No. 5, 2004, pp. 714-721. http://dx.doi.org/10.1359/jbmr.2004.19.5.714

[71] R. C. Morris Jr., “An Experimental Renal Acidification Defect in Patients with Hereditary Fructose Intolerance: II. Its Distinction from Classic Renal Tubular Acidosis; Its Resemblance to the Renal Acidification Defect Associated with the Fanconi Syndrome of Children with Cystinosis,” Journal of Clinical Investigation, Vol. 47, No. 7, 1986, pp. 1648-1663. http://dx.doi.org/10.1172/JCI105856

[72] A. Nissenkorn, S. H. Korman, O. Vardi, A. Levine, Z. Katzir, A. Ballin and T. Lerman-Sagie, "Carnitine-Deficient Myopathy as a Presentation of Tyrosinemia Type I," Journal of Child Neurology, Vol. 16, No. 9, 2001, pp. 642-644. http://dx.doi.org/10.1177/088307380101600903

[73] D. Muller, R. Santer, M. Krawinkel, B. Christiansen and J. Schaub, "Fanconi-Bickel Syndrome Presenting in Neona- tal Screening for Galactosaemia," Journal of Inherited Metabolic Disease, Vol. 20, No. 4, 1997, pp. 607-608.

[74] P. Monro, "Effect of Treatment on Renal Function in Severe Osteomalacia Due to Wilson's Disease," Journal of Clinical Pathology, Vol. 23, No. 6, pp. 487-491. http://dx.doi.org/10.1136/jcp.23.6.487

[75] N. M. Papadopoulos, R. Costello, L. Charnas, M. D. Adamson and W. A. Gahl, "Electrophoretic Examination of Proteinuria in Lowe's Syndrome and Other Causes of Renal Tubular Fanconi Syndrome,” Clinical Chemistry, Vol. 35, No. 11, 1989, pp. 2231-2233.

[76] O. N. Elpeleg, “The Molecular Background of Glycogen Metabolism Disorders," Journal of Pediatric Endocrinology and Metabolism, Vol. 12, No. 3, 1999, pp. 363379. http://dx.doi.org/10.1515/JPEM.1999.12.3.363

[77] R. G. Adams, J. F. Harrison and P. Scott, "The Development of Cadmium-Induced Proteinuria, Impaired Renal Function, and Osteomalacia in Alkaline Battery Workers,” Quarterly Journal of Medicine, Vol. 38, No. 152, 1969, pp. 425-443.

[78] D. S. Rao, A. M. Parfitt, A. R. Villanueva and P. J. Dorman and M. Kleerekoper, "Hypophosphatemic Osteomalacia and Adult Fanconi Syndrome Due to Light-Chain Nephropathy: Another Form of Oncogenous Osteomalacia,” American Journal of Medicine, Vol. 82, No. 2, 1987, pp. 333-338.

http://dx.doi.org/10.1016/0002-9343(87)90081-7

[79] J. Z. Melnick, M. Baum and J. R. Thompson, “Aminoglycoside-Induced Fanconi’s Syndrome,” American Journal of Kidney Disease, Vol. 23, No. 1, 1994, pp. 118-122.

[80] J. Kapadia, S. Shah, C. Desai, M. Desai, S. Patel, A. N. Shah and R. K. Dikshit, "Tenofovir Induced Fanconi Syndrome: A Possible Pharmacokinetic Interaction,” Indian Journal of Pharmacology, Vol. 45, No. 2, 2013, pp. 191192.

[81] J. M. Irizarry-Alvarado, J. P. Dwyer, L. M. Brumble, S. Alvarez and J. C. Mendez, "Proximal Tubular Dysfunction Associated with Tenofovir and Didanosine Causing Fanconi Syndrome and Diabetes Insipidus: A Report of 3 Cases,” The AIDS Reader, Vol. 19, No. 3, 2009, pp. 114121.

[82] G. Mathew and S. J. Knaus, “Acquired Fanconi’s Syndrome Associated with Tenofovir Therapy," Journal of General Internal Medicine, Vol. 21, No. 11, 2006, pp. C3C5. http://dx.doi.org/10.1111/j.1525-1497.2006.00518.x

[83] H. Peyrière, J. Reynes, I. Rouanet, N. Daniel, C. M. de Boever, J. M. Mauboussin, H. Leray, L. Moachon, D. Vincent and D. Salmon-Céron, "Renal Tubular Dysfunction Associated with Tenofovir Therapy: Report of 7 Cases,” Journal of Acquired Immune Deficiency Syndrome, Vol. 35, No. 3, 2004, pp. 269-273.

[84] M. Saumoy, F. Vidal, J. Peraire, S. Sauleda, A. Vea, C. Viladés, E. Ribera and C. Richart, “ Proximal Tubular Kidney Damage and Tenofovir: A Role for Mitochondrial Toxicity?” AIDS, Vol. 18, No. 12, 2004, pp. 1741-1748. http://dx.doi.org/10.1097/01.aids.0000131386.38103.37

[85] C. Creput, G. Gonzalez-Canali, G. Hill, C. Piketty, M. Kazatchkine and D. Nochy, "Renal Lesions in HIV-1Positive Patient Treated with Tenofovir,” AIDS, Vol. 17, 
No. 6, 2003, pp. 935-937. http://dx.doi.org/10.1097/00002030-200304110-00026

[86] T. Olea, S. Azorin, C. Hevia, R, Regojo, M. Luz Picazo, et al., "Tenofovir-Induced Fanconi Syndrome and Renal Failure,” Portuguese Journal of Nephrology and Hypertension, Vol. 22, No. 3, 2008, pp. 267-269.

[87] P. P. Kapitsinou and N. Ansari, “Acute Renal Failure in an AIDS Patient on Tenofovir: A Case Report,” Journal of Medical Case Reports, Vol. 2, 2008, p. 94.

[88] B. Schaaf, S. P. Aries, E. Kramme, J. Steinhoff and K. Dalhoff, “Acute Renal Failure Associated with Tenofovir Treatment in a Patient with Adquired Immunodeficiency Syndrome,” Clinical Infectious Disease, Vol. 37, No. 3, 2003, pp. e41-e43. http://dx.doi.org/10.1086/376643

[89] S. M. Patel, T. R. Zembower, F. Palella, Y. S. Kanwar and S. N Ahya, "Early Onset of Tenofovir-Induced Renal Failure: Case Report and Review of the Literature," Scientific World Journal, Vol. 7, 2007, pp. 1140-1148. http://dx.doi.org/10.1100/tsw.2007.164

[90] J. C. Lee, and R. D. Marasok, "Acute Tubular Necrosis in a Patient Receiving Tenofovir,” AIDS, Vol. 17, No. 17, 2003, pp. 2543-2545. http://dx.doi.org/10.1097/00002030-200311210-00021

[91] A. E. Zimmermann, T. Pizzoferrato, J. Bedford, A. Morris, R. Hoffman and G. Braden, "Tenofovir-Associated Acute and Chronic Kidney Disease: A Case of Multiple Drug Interactions,” Clinical Infectious Disease, Vol. 42, No. 2, 2006, pp. 283-290. http://dx.doi.org/10.1086/499048

[92] D. Verhelst, M. Monge, J. Meynard, B. Fouqueray, B. Mougenot, P.-M. Girard, P. Ronco and J. Rossert, "Fanconi’s Syndrome and Renal Failure Induced by Tenofovir: A First Case Report," American Journal of Kidney Disease, Vol. 40, No. 6, 2002, pp. 1331-1333. http://dx.doi.org/10.1053/ajkd.2002.36924

[93] A. Karras, M. Lafaurie, A. Furco, A. Bourgarit, D. Droz, D. Sereni, C. Legendre, F. Martinez and J.-M. Molina, "Tenofovirrelated Nephrotoxicity in Human Immunodeficiency Virus-Infected Patients: Three Cases of Renal Failure, Fanconi Syndrome, and Nephrogenic Diabetes Insipidus,” Clinical Infectious Disease, Vol. 36, No. 8, 2003, pp. 1070-1073. http://dx.doi.org/10.1086/368314

[94] G. Gaspar, A. Monereo, A. Garcia-Reyne and M. de Guzmán, "Fanconi Syndrome and Acute Renal Failure in a Patient Treated with Tenofovir: A Call for Caution," AIDS, Vol. 18, No. 2, 2004, pp. 351-352. http://dx.doi.org/10.1097/00002030-200401230-00035

[95] S. Callens, A. De Roo and R. Colebunders, "Letter to the Editor-Fanconi-Like Syndrome and Rhabdomyolysis in a person with HIV Infection on Highly Active Antiretroviral Therapy Including Tenofovir," Journal of Infection, Vol. 47, No. 3, 2003, pp. 262-263. http://dx.doi.org/10.1016/S0163-4453(03)00082-3

[96] S. R. Brian and A. P. Mark, "Tenofovir-Associated Nephrotoxicity: Fanconi Syndrome and Renal Failure,” American Journal Medicine, Vol. 117, No. 4, 2004, pp. 282284. http://dx.doi.org/10.1016/j.amjmed.2004.03.025

[97] C. W. James, M. C. Steinhaus, S. Szabo and R. M. Dressler, "Tenofovir-Related Nephrotoxicity: Case Report and Re- view of the Literature,” Pharmacotherapy, Vol. 24, No. 3, 2004, pp. 414-418.

http://dx.doi.org/10.1592/phco.24.4.415.33182

[98] S. Nidhi, “Concept of Drug Interaction,” International Research Journal of Pharmacy Vol. 3. No. 7, 2012, pp. 120122.

[99] S. Marcotte, A. Talbot and B. Trottier, "Acute Renal Failure in Four HIV Infected Patients: Potential Association with Tenofovir and Nonsteroidal Anti-Inflammatory Drugs," Canadian Journal of Infectious Diseases \& Medical Microbiology, Vol. 19, No. 1, 2008, pp. 75-76.

[100] M. Bickel, P. Khaykin, C. Stephen, K. Schmidt, M. Buettner, K. Amann, T. Lutz, P. Gute, A. Haberl, H. Geiger, H. R. Brodt and O. Jung, “Acute Kidney Injury Caused by Tenofovir Disoproxil Fumarate and Diclofenac CoAdministration,” HIV Medicine, Vol. 14, No. 10, 2013, pp. 633-638. http://dx.doi.org/10.1111/hiv.12072

[101] S. Schaller and B. S. Kaplan, “Acute Nonoliguric Renal Failure in Children Associated with Nonsteroidal Antiinflammatory Agents,” Pediatric Emergency Care, Vol. 14, No. 6, 1998, pp. 416-418. http://dx.doi.org/10.1097/00006565-199812000-00011

[102] A. A. Edin, A. A. Shaheen, H. M. Elgawad and N. I. Shehata, "Protective Effect of Taurine and Guercetin against Renal Dysfunction Associates with Combine Use of Gentamicin and Diclofenac,” Indian Journal of Biochemistry and Biophysics, Vol. 45, No. 5, 2008, pp. 332-340.

[103] L. Kovacevic, J. Bernstein, R. P. Valentini, A. Imam, N. Gupta and T. K. Mattoo, "Renal Papillary Necrosis Induced by Naproxen,” Pediatric Nephrology, Vol. 18, No. 8, 2003, pp. 826-829. http://dx.doi.org/10.1007/s00467-003-1167-4

[104] P. E. Kulling, E. A. Backman, A. S. Skagius and E. A. Beckman, "Renal Impairment after Acute Diclofenac, Naproxen, and Sulindac Overdoses," Journal of ToxicologyClinical Toxicology., Vol. 33, No. 2, 1995, pp. 173-177.

[105] O. S. Onay, H. S. Erçoban, U. S. Bayrakci, E. Melek, N. Cengiz and E. Baskin, "Acute, Reversible Nonoliguric Renal Failure in Two Children Associated with Analgesic-Antipyretic Drugs,” Pediatric Emergency Care, Vol. 25, No. 4, 2009, pp. 263-266. http://dx.doi.org/10.1097/PEC.0b013e31819e38d4

[106] S. Andalib, A. M. Naem, A. Garjani, N. Ahmadi Asl and A. Addolahi, "Comparative Study Pertaining to Deleterious Effect of Diclofenac Sodium and Meloxicam on Kidney Tissue in Rats,” Experimental and Clinical Science Journal, Vol. 10, 2011, pp. 149-154.

[107] G. Ayadin, A. G. Mera, E. Cikem and N. Karahan, "Histopathological Changes in Liver and Renal Tissue Induced by Different Doses of Diclofenac Sodium in Rats," Turkish Journal of Veterinary and Animal Science, Vol. 27, 2003, pp. 1131-1140.

[108] Z. K. EL-Maddawy and I. M. EL-Ashmawy, "HepatoRenal and Hematological Effect of Diclofenac Sodium in Rats,” Global Journal of Pharmacology, Vol. 7, No. 2, 2013, pp. 123-132.

[109] K. Thangapandian, "Ibuprofen Induced Nephrotoxicity in Adult Albino Rats," International Journal of Advance Life Science, Vol. 1, 2012, pp. 58-67. 
[110] M. O. Abata, I. Lateef and V. O. Taiwo, “Toxic Effect of Non Steroidal Antiinflammatory Agents in Rats," African Journal of Biomedical Research, Vol. 9, 2006, pp. 219233.

[111] M. A. Perazella and G. K. Buller, "Can Ibuprofen Cause Acute Renal Failure in a Normal Individual? A Case of Acute Overdose," American Journal of Kidney Disease, Vol. 18, No. 5, 1991, pp. 600-602.

[112] C. Kenyon, N. Wearne, R. Burton and G. Meintjes, "The Risks of Concurrent Treatment with Tenofovir and Aminoglycosides in Patients with HIV-Associated Tuberculosis," South African Journal of HIV Medicine, Vol. 12, No. 1, 2011, pp. 43-45.

[113] J. P. Olivera, C. A. Silva, C. D. Barbieri, G. M. Olivieira, D. M. T. Zanetta and E. A. Burdmann, "Prevalence and Risk Factors for Aminoglycoside Nephrotoxicity in Intensive Care Unit," Antimicrobial Agents Chemotherapy, Vol. 53, No. 7, 2009, pp. 2887-2891. http://dx.doi.org/10.1128/AAC.01430-08

[114] J. S. Bertino, L. A. Booker, P. A. Franck, P. L. Jenkins, K. R. Franck and A. N. Nafziger, "Incidence of and Significant Risk Factors for Aminoglycoside-Associated Nephrotoxicity in Patients Dosed by Using Individualized Pharmacokinetic Monitoring," Journal of Infectious Disease, Vol. 167, No. 1, 1993, pp. 173-179. http://dx.doi.org/10.1093/infdis/167.1.173

[115] D. Beauchamp, G. Laurent, L. Grenier, J. Zanen, J. A. Heuson-Stiennon and M. G. Bergeron, "Attenuated of Gentamicin-Induced Nephrotoxicity in Rats by Feroxacin," Antimicrobial Agents and Chemotheraphy, Vol. 41, No. 6, 1997, pp. 1237-1245.

[116] O. Bella and A. Chuka, "Dose Dependent Amelioration of Gentamicin Induced Nephrotoxicity in Adult Albino Rats by Vitamin B Complex-A Preliminary Study," Tropical Journal of Pharmaceutical Research, Vol. 8, No. 2, 2009, pp. 111-116.

[117] C. Martinez-Salgado, F. J. Lopez-Hernandez and J. M. Lopez-Novia, "Glomerular Nephrotoxicity of Aminoglycosides,” Toxicity and Applied Pharmacology, Vol. 223, No. 1, 2007, pp. 86-98.

[118] M. P. Mingeot-Leclercg and P. M. Tulkerns, "Aminoglycoside: Nephrotoxicity,” Antimicrobial Agents Chemotherapy, Vol. 43, No. 5, 1999, pp. 1003-1012.

[119] C. Martínez-Salgado, F. J. López-Hernández and J. M. López-Novoa, "Glomerular Nephrotoxicity of Aminoglycosides,” Toxicology and Applied Pharmacology, Vol. 223, No. 1, 2007, pp. 86-98. http://dx.doi.org/10.1016/j.taap.2007.05.004

[120] T. Samadian, A. R. Debpour, S. Amini and P. Nouhnejad, "Inhibition of Gentamicin Induced Nephrotoxicity by Lithium in Rats," Histology and Histopathology, Vol. 8, No. 1, 1993, pp. 139-147.

[121] M. M. Khalaf, S. S. Ghaleb and M. F. Abbas, "Protective Effect of Carnosine on Amikacin-Induced Nephrotoxicity in Rats," Mansoura Journal of Forensic Medical and Clinical Toxicology, Vol. 18, No. 1, 2010, pp. 81-89.

[122] S. K. Gupta, J. A. Eustace, J. A. Winston, et al., “Guidelines for the Management of Chronic Kidney Disease in HIV-Infected Patients: Recommendations of the HIV Me- dicine Association of the Infectious Diseases Society of America," Clinical Infectious Disease, Vol. 40, No. 11, 2005, pp. 1559-1585. http://dx.doi.org/10.1086/430257

[123] HIV/AIDS Treatment Guidelines/AIDSinfo. aidsinfo.nih. gov/guidelines.

[124] E. S. Perloff, S. X. Duan, P. R. Skolnik, et al., “Atazanavir: Effects on P-gp Transport and CYP3A Metabolism in Vitro,” Drug Metababolism and Disposition, Vol. 33, No. 6, 2005, pp. 764-770. http://dx.doi.org/10.1124/dmd.104.002931

[125] "The European Agency for the Evaluation of Medicinal Products,” Press Office London, 2005.

[126] A. M. Taburet, C. Piketty, C. Chazallon, I. Vincent, L. Gérard, V. Calvez, F. Clavel, J.-P. Aboulker and P.-M. Girard, "Interactions between Atazanavir-Ritonavir and Tenofovir in Heavily Pretreated Human Immunodeficiency Virus-Infected Patients," Antimicrobial Agents Chemotherapy, Vol. 48, No. 6, 2004, pp. 2091-2096. http://dx.doi.org/10.1128/AAC.48.6.2091-2096.2004

[127] M. A. Crowther, W. Callaghan, A. B. Hodsman and I. D. Mackie, "Dideoxyinosine-Associated Nephrotoxicity,” AIDS, Vol. 7, No. 1, 1993, pp. 131-132. http://dx.doi.org/10.1097/00002030-199301000-00024

[128] G. D’Ythurbide, C. Goujard, F. Mechai, A. Blanc, B. Charpentier and R. Snanoudj, "Fanconi Syndrome and Nephrogenic Diabetes Insipidus Associated with Didanosine Therapy and Literature Review," Nephrology Dialysis Transplantation, Vol. 22, No. 12, 2007, pp. 3656-3659.

[129] S. Hussain, A. Khayat, A. Tolaymat and M. H. Rathore, "Nephrotoxicity in a Child with Perinatal HIV on Tenofovir, Didanosine and Lopinavir/Ritonavir," Pediatric Nephrology, Vol. 21, No. 7, 2006, pp. 1034-1036. http://dx.doi.org/10.1007/s00467-006-0109-3

[130] F. Rollot, E. M. Nazal, L. Chauvelot-Moachon, C. Kélaïdi, N. Daniel, M. Saba, S. Abad and P. Blanche, "Tenofovirrelated Fanconi Syndrome with Nephrogenic Diabetes Insipidus in a Patient with Acquired Immunodeficiency Syndrome: The Role of Lopinavir-Ritonavir-Didanosine," Clinical Infectious Disease, Vol. 37, No. 12, 2003, pp. e174-e176. http://dx.doi.org/10.1086/379829

[131] C. Creput, G. Gonzalez-Canali, G. Hill, C. Piketty, M. Kazatchkine and D. Nochy, "Renal Lesions in HIV-1-Positive Patient Treated with Tenofovir,” AIDS, Vol. 17, No. 6, 2003, pp. 935-937.

[132] “Viread (Tenofovir Disoproxil Fumarate),” Gilead Sciences, Foster City, 2005.

[133] D. J. Back, D. M. Burger, C. W. Flexner and J. G. Gerber, "The Pharmacology of Antiretroviral Nucleoside and Nucleotide Reverse Transcriptase Inhibitors,” Journal of Acquired Immune Deficiency Syndrome, Vol. 39, 2005, pp. S1-S23. http://dx.doi.org/10.1097/01.qai.0000168882.67942.3f

[134] F. Vidal, J. C. Domingo, J. Guallar, M. Saumoy, B. Cordobilla, R. S. de la Rosa, M. Giralt, M. L. Álvarez, M. López-Dupla, F. Torres, F. Villarroya, T. Cihlar and P. Domingo, "In Vitro Cytotoxicity and Mitochondrial Toxicity of Tenofovir Alone and in Combination with Other antiretrovirals in Human Renal Proximal Tubule Cells," Antimicrobial Agents Chemotherapy, Vol. 50, No. 11, 2006, 
pp. 3824-3832. http://dx.doi.org/10.1128/AAC.00437-06

[135] M. R. Nelson, C. Katlama, J. S. Montaner, et al., "The Safety of Tenofov Disoproxil Fumarate for the Treatment of HIV Infection in Adults: The First 4 Years,” AIDS, Vol. 21, No. 10, 2007, pp. 1273-1281. http://dx.doi.org/10.1097/QAD.0b013e3280b07b33

[136] G. Madeddu, P. Bonfanti, G. V. De Socio, S. Carradori, C. Grosso, P. Marconi, G. Penco, E. Rosella, S. Miccolis, S. Melzi, M. S. Mura, S. Landonio, E. Ricci and T. Quirino, "Tenofovir Renal Safety in HIV-Infected Patients: Results from the SCOLTA Project,” Biomedicine \& Pharmacotherapy, Vol. 62, No. 1, 2008, pp. 6-11. http://dx.doi.org/10.1016/j.biopha.2007.04.008

[137] US Renal Data System (USRDS), “USRDS 2001 Annual Data Report," Bethesda MD, The National Institutes of Health, National Institute of Diabetes and Digestive and Kidney Diseases, 2001.

[138] A. I. Choi, R. A. Rodriguez, P. Bacchetti, D. Bertenthal, P. A. Volberding and A. M. O’Hare, "Racial Differences in End-Stage Renal Disease Rates in HIV Infection versus Diabetes,” Journal of American Society of Nephrology, Vol. 18, No. 11, 2007, pp. 2968-2974. http://dx.doi.org/10.1681/ASN.2007040402

[139] G. Lucas, B. Lau, M. Atta, D. Fine, J. Keruly, and R. Moore, "Chronic Kidney Disease Incidence and Progression to End-Stage Renal Disease, in HIV-Infected Individuals: A Tale of Two Races," Journal of Infectious Disease, Vol. 197, No. 11, 2008, pp. 1548-1557. http://dx.doi.org/10.1086/587994

[140] S, Rodríguez-Nóvoa, P. Labarga, V. Soriano, D. Egan, M. Albalater, J. Morello, L. Cuenca, G. González-Pardo, S. Khoo, D. Back and A. Owen, "Predictors of Kidney Tubular Dysfunction in HIV-Infected Patients Treated with Tenofovir: A Pharmacogenetic Study," Clinical Infectious Diseases, Vol. 48, No. 11, 2009, pp. e108-e116. http://dx.doi.org/10.1086/598507

[141] H. Izzedine, J. Hulot, E. Villard, C. Goyenvalle, S. Dominguez, J. Ghosn, M. A. Valantin, P. Lechat and G. Deray, "Association between ABCC2 Gene Haplotypes and Tenofovir-Induced Proximal Tubulopathy,” The Journal of Infectious Diseases, Vol. 194, No. 11, 2006, pp. 14811491. http://dx.doi.org/10.1086/508546

[142] S. P. Pushpakom, N. J. Liptrott, S. Rodríguez-Nóvoa, P. Labarga, V. Soriano, M. Albalater, E. Hopper-Borge, S. Bonora, G. Di Perri, D. J. Back, S. Khoo, M. Pirmohamed and A. Owen, "Genetic Variants of ABCC10, a Novel Tenofovir Transporter, Are Associated With Kidney Tubular Dysfunction,” The Journal of Infectious Diseases, Vol. 204, No. 1, 2011, pp. 145-153. http://dx.doi.org/10.1093/infdis/jir215

[143] T. Nishijima, H. Komatsu, K. Higasa, M. Takano, K. Tsuchiya, T. Hayashida, S. Oka and H. Gatanaga, "Single Nucleotide Polymorphisms in ABCC2 Associate With Tenofovir-Induced Kidney Tubular Dysfunction in Japanese Patients with HIV-1 Infection: A Pharmacogenetic Study, Clinical Infectious Diseases, Vol. 55, No. 11, 2012, pp. 1558-1567. http://dx.doi.org/10.1093/cid/cis772

[144] G. Birkus, M. J. Hitchcock and T. Cihlar, “Assessment of Mitochondrial Toxicity in Human Cells Treated with Tenofovir: Comparison with Other Nucleoside Reverse Tran- scriptase Inhibitors," Antimicrobial Agents and Chemotherapy, Vol. 46, No. 3, 2002, pp. 716-723. http://dx.doi.org/10.1128/AAC.46.3.716-723.2002

[145] T. Cihlar, A. S. Ray, G. Laflamme, J. E. Vela, L. Tong, M. D. Fuller, A. Roy and G. R. Rhodes, "Molecular Assessment of the Potential for Renal Drug Interactions between Tenofovir and HIV Protease Inhibitors," Antiviral Therapy, Vol. 12, No. 2, 2007, pp. 267-272.

[146] H. C. Cote, A. B. Magil, M. Harris, B. J. Scarth, I. Gadawski, N. Wang, E. Yu, B. Yip, N. Zalunardo, R. Werb, R. Hogg, P. R. Harrigan and J. S. Montaner, "Exploring Mitochondrial Nephrotoxicity as a Potential Mechanism of Kidney Dysfunction among HIV-Infected Patients on Highly Active Antiretroviral Therapy," Antiviral Therapy, Vol. 11, No. 1, 2006, pp. 79-86.

[147] A. B. Liborio, L. Andrade, L. B. Pereira, T. C. Sanches, M. H. Shimizu and A. C. Seguro, "Rosiglitazone Reverses Tenofovir-Induced Nephrotoxicity,” Kidney International, Vol. 74, 2008, pp. 910-918. http://dx.doi.org/10.1038/ki.2008.252

[148] J. J. Kohler, S. H. Hosseini, A. Hoying-Brandt, E. Green, D. M. Johnson, R. Russ, D. Tran, C. M. Raper, R. Santoianni and W. Lewis, "Tenofovir Renal Toxicity Targets Mitochondria of Renal Proximal Tubules,” Laboratory Investigation, Vol. 89, 2009, pp. 513-519. http://dx.doi.org/10.1038/labinvest.2009.14

[149] D. Lebrecht, A. C. Venhoff, J. Kirschner, T. Wiech, N. Venhoff and U. A. Walker, "Mitochondrial Tubulopathy in Tenofovir Disoproxil Fumarate-Treated Rats,” Journal of Acquired Immune Deficiency Syndrome, Vol. 51, No. 3, 2009, pp. 258-263.

http://dx.doi.org/10.1097/QAI.0b013e3181a666eb

[150] M. L. Circu and T. Y. Aw, "Reactive Oxygen Species, Cellular Redox Systems, and Apoptosis,” Free Radical Biology and Medicine, Vol. 48, No. 6, 2010, pp. 749-762. http://dx.doi.org/10.1016/j.freeradbiomed.2009.12.022

[151] M. C. Dalakas, I. Illa, G. H. Pezeshkpour, J. P. Laukaitis, B. Cohen and J. L. Griffin, "Mitochondrial Myopathy Caused by Long-Term Zidovudine Therapy,” New England Journal of Medicine, Vol. 322, No. 16, 1990, pp. 1098-1105. http://dx.doi.org/10.1056/NEJM199004193221602

[152] I. Dalle-Donne, G. Aldini, M. Carini, R. Colombo, R. Rossi and A. Milzani, "Protein Carbonylation, Cellular Dysfunction, and Disease Progression,” Journal of Cellular and Molecular Medicine, Vol. 10, No. 2, 2006, pp. 389-406. http://dx.doi.org/10.1111/j.1582-4934.2006.tb00407.x

[153] M. Marí, A. Morales, A. Colell, C. García-Ruiz and J. C. Fernández-Checa, "Mitochondrial Glutathione, a Key Survival Antioxidant," Antioxidants and Redox Signaling, Vol. 11, No. 11, 2009, pp. 2685-2700. http://dx.doi.org/10.1089/ars.2009.2695

[154] N. Güngör, R. L. Godschalk, D. M. Pachen, F. J. Van Schooten and A. M. Knaapen, “Activated Neutrophils Inhibit Nucleotide Excision Repair in Human Pulmonary Epithelial Cells: Role of Myeloperoxidase,” Federation of American Societies for Experimental Biology, Vol. 21, No. 10, 2007, pp. 2359-2367.

http://dx.doi.org/10.1096/fj.07-8163com 
[155] H. Ramamoorthy, P. Abraham and B. Isaac, "Oxidative Stress, Decreased Activities of Anti-Oxidant Enzymes, and Neutrophil Infiltration Contribute to Tenofovir Diso- proxil Fumarate Induced Renal Damage in Rats,” International Research of Pharmacy and Pharmacology, Vol. 1, No. 10, 2011, pp. 259-270. 